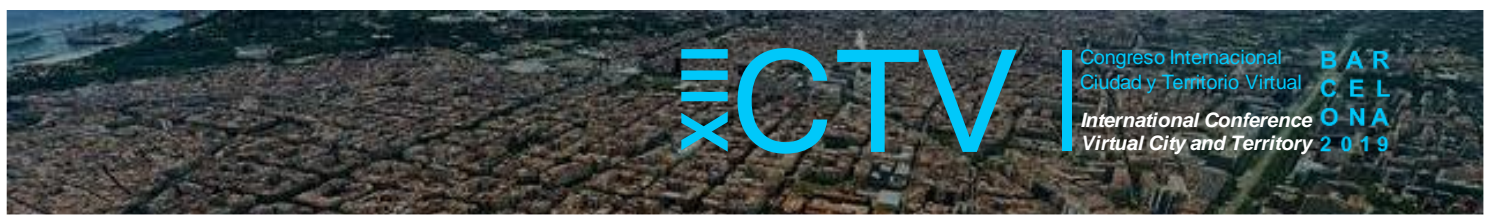

\title{
LA RECONVERSIÓN DE LAS FACHADAS MARÍTIMAS URBANAS PORTUARIAS: EL CASO DE ALICANTE
}

\author{
Olga Grao Gil ${ }^{1 *}$
}

Remisión inicial: 2019-07-16; Remisión definitiva: 2019-09-30; Publicación: 2019-12-21

Citación: Grao Gil, O. (2019). La reconversión de las fachadas marítimas urbanas portuarias: el caso de Alicante. En XIII CTV 2019 Proceedings: XIII International Conference on Virtual City and Territory: "Challenges and paradigms of the contemporary city": UPC, Barcelona, October 2-4, 2019. Barcelona:CPSV, 2019, p. 8570.E-ISSN2604-6512.DOI http://dx.doi.org/10.5821/ctv.8570

\section{Resumen}

Las fachadas marítimas, concebidas en épocas pasadas como espacios meramente defensivos y a menudo residuales ligados al puerto, se han convertido hoy en día en escaparate de las ciudades costeras y foco de atracción de su predominante actividad turística.

Como caso de estudio se analiza la ciudad de Alicante, capital de la provincia homónima de la región valenciana y destacado enclave portuario con larga tradición mercantil en el litoral Mediterráneo. A mediados del siglo XIX, Alicante fue la primera localidad marítima española comunicada por ferrocarril con la capital —Madrid—, con las importantes consecuencias de toda índole que ello acarreó. Gracias a los avances en las comunicaciones, se produjo la apertura de la costa a los habitantes del interior, que comenzaron a desplazarse al litoral para tomar los baños de mar como fuente de salud, tan de moda en aquellos años. Al mismo tiempo, la ciudad dejó de ser plaza militar, lo que permitió el derribo de las murallas defensivas que la constreñían impidiendo su normal crecimiento. Por todo ello, Alicante puede considerarse paradigma de ciudad costera mediterránea en su desarrollo desde su estructura de urbe portuaria amurallada hasta su configuración como destino turístico de referencia en el Levante español.

El objetivo de este estudio es analizar la evolución que ha tenido el frente marítimo alicantino, partiendo de sus orígenes defensivos, pasando por la creación de los paseos litorales a finales del siglo XIX, hasta llegar a su estructura urbana actual. La metodología seguida se basa en el estudio pormenorizado de todos los elementos que forman o han formado parte de la fachada marítima, entendido siempre dentro de su contexto histórico. El ámbito temporal, si bien abarca desde los primeros lienzos de muralla costera de época musulmana, se centra principalmente en el período comprendido desde el derribo de las murallas de la ciudad, a mediados del siglo XIX, hasta nuestros días. Con respecto al ámbito espacial, la investigación se refiere a la fachada marítima propiamente urbana que enmarca el centro histórico y que se halla acotada en sus extremos por dos antiguas estaciones de ferrocarril, la de La Marina -al noreste- y la de Murcia - al sureste-, como hitos históricos en recuerdo de la importancia que en su día tuvo el ferrocarril en el desarrollo del frente litoral. Coincidente con los tres paseos que existen en la actualidad, se considera la fachada marítima dividida en tres tramos diferenciados, de norte a sur: Gómiz-Explanada-Canalejas, con una longitud total aproximada de $2 \mathrm{~km}$.

La hipótesis de partida planteada es que la generación de los paseos marítimos y, en definitiva, la urbanización del interfaz ciudad-mar, es consecuencia de un cambio funcional del frente litoral. Tras varios siglos de función defensiva, materializada en las murallas de la costa, y de función mercantil, sirviendo de entorno al puerto, en la fachada marítima de Alicante predominó la función lúdico-representativa, al mismo tiempo que comenzaban a llegar los cada vez más numerosos bañistas en búsqueda de los beneficios de las aguas marinas en la segunda mitad del siglo XIX. A los visitantes de balneario les siguieron, cuando éstos entraron en declive, los turistas de sol y playa a partir de los años 60 y 70 del siglo XX, convirtiendo Alicante en destino elegido para pasar las vacaciones junto al mar y segunda residencia de buena parte de los habitantes del interior de la península. Este rol lúdico-representativo se compaginó durante más de una centuria con el comercial, hasta que en los años 90 del pasado siglo la actividad portuaria se trasladó definitivamente al sur de la urbe, quedando la dársena histórica para el atraque de embarcaciones náuticas y de recreo, como apunte anecdótico de la ciudad portuaria que en el pasado fue.

El interés del estudio radica en que gran parte de las conclusiones extraídas de la investigación, en cuanto a la reconversión de la fachada marítima en otros usos y la consecuente repercusión en el resto de la ciudad, son

1 Doctora Arquitecta. Profesora de Urbanismo en el Departamento de Edificación y Urbanismo de la Universidad de Alicante, https://orcid.org/0000-0003-1994-9331. Correo de contacto: olgagrao@gmail.com 


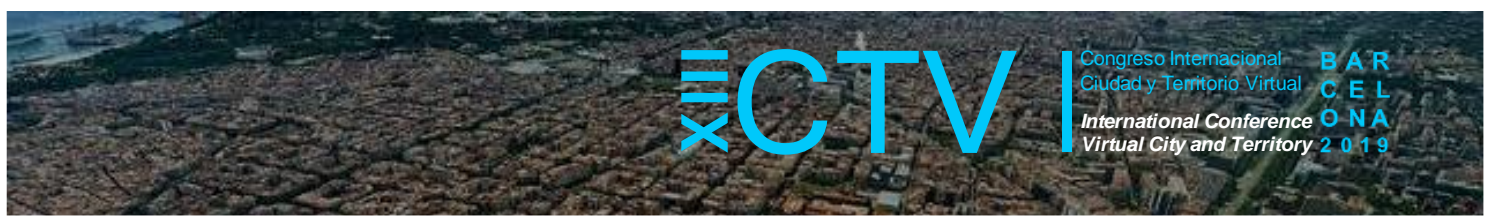

extrapolables a otras urbes costeras de similares características, con tradición portuaria, convertidas en lugares con importante actividad turística en la actualidad.

\section{Abstract}

The seafronts of the cities, conceived in past times as merely defensive and often residual spaces linked to the port, have nowadays become a showcase for coastal cities and hubs for their prevailing tourist activity.

The city of Alicante, capital of the homonymous province of the Valencian region and an important seaport enclave with a long commercial tradition in the Mediterranean Sea, is analyzed as a case study. In the mid-nineteenth century, Alicante was the first Spanish maritime city connected by rail with the capital —Madrid-, with the relevant consequences of all sorts that this entailed. Advances in communications resulted in the opening of the coast to the inhabitants of the interior, who began to move to the coast to take the sea baths as a source of health, so fashionable in those years. At the same time, the city ceased to be a military stronghold, which allowed the demolition of the defensive walls that constrained the city preventing its normal growth. For all these reasons, Alicante can be considered a paradigm of a Mediterranean coastal city in its evolution from its walled harbour city structure to its configuration as a reference tourist destination in the Spanish Levante.

The aim of this study is to analyse the evolution of the Alicante maritime front, starting from its defensive origins, passing through the creation of seafront promenades at the end of the nineteenth century, until reaching the current urban structure. The methodology followed is based on the detailed study of all the elements that are part of the maritime facade, always understood within its historical context. The temporal scope, although it ranges from the first Muslim-era coastal walls, focuses mainly on the period from the demolition of the city walls, in the mid-nineteenth century, to the present day. With regard to the space field, the study refers to the proper urban maritime facade that frames the historic centre and is bounded at its ends by two old railway stations, La Marina Station - to the northeastand Murcia Station - to the southeast-, as historical milestones in remembrance of the importance of the railway in the development of the coastal front. Coinciding with the three existing promenades at present, the seafront is considered divided into three different sections, from north to south: Gómiz-Explanada-Canalejas, with a total length of approximately $2 \mathrm{~km}$.

The initial hypothesis is that the generation of the promenades and, eventually, the urbanization of the city-sea interface, is a consequence of a functional change of the coastline. After several centuries of defensive function, materialized in the walls of the coast, and of mercantile function, serving as surroundings to the port, on the seafront of Alicante dominated the playful-representative function, while the increasingly numerous bathers began to arrive in search of the benefits of sea water in the second half of the nineteenth century. The spa visitors were followed, when spas went into decline, by sun and beach tourists from the 60 s and 70 s, making Alicante the chosen destination to spend the holidays by the sea and second residence of many inhabitants of the interior of the peninsula. This playful-representative role was combined for more than a century with the commercial one, until in the 90 s of the last century the port activity was definitely moved to the south of the city, leaving the historic dock for nautical and recreational boats, as anecdotal record of the port city that in the past was.

The interest of the study is that much of the conclusions drawn from the research, regarding the conversion of the sea façade into other uses and the consequent impact on the rest of the city, could be extrapolated to other coastal cities of similar characteristics, with port tradition, turned into places of major tourist activity today.

Palabras Clave: fachada marítima; frente litoral; Alicante; interfaz ciudad-mar

Key words: maritime façade; waterfront; Alicante; city-sea interface

\section{Introducción}

El mar Mediterráneo cuenta con numerosas ciudades costeras, surgidas al amparo de las bondades naturales y climatológicas de su emplazamiento, que se desarrollaron junto al litoral hasta conformar las metrópolis actuales. Urbes como Cartagena, Alicante, Tarragona, Barcelona, Marsella o Génova -entre otras muchas-que comparten no sólo un mismo mar y un clima común, sino también una misma herencia cultural, histórico-artística, religiosa, gastronómica, etc., y una tradición comerciante y portuaria que la proximidad a la costa favoreció. Todas ellas guardan semejanzas en relación a la evolución morfológica urbana, con 


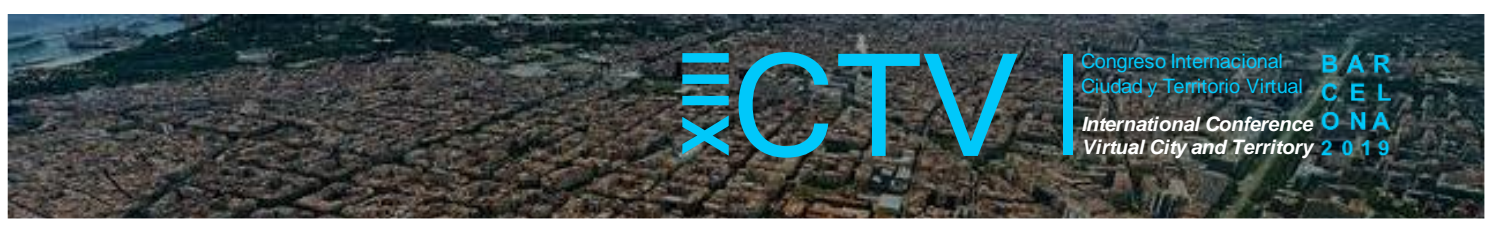

núcleos históricos amurallados en origen que se articularon en torno al litoral, desarrollando una fachada marítima en el interfaz ciudad-mar que se fue transformando a lo largo de los siglos.

La relación de las ciudades costeras del arco mediterráneo con el mar ha sido desigual en el tiempo. Los moradores de los primitivos asentamientos han tratado de obtener los beneficios naturales y mercantiles que el mar ofrecía, a la vez que se protegían de él por ser el medio preferido por el eventual enemigo por el que dirigir sus ataques. Es por ello que la fachada marítima de estas ciudades tuvo en sus inicios una eminente función defensiva, compaginada con el rol de servir de entorno al puerto -importante motor económico-, hasta que se procedió al derribo de los elementos defensivos, a partir del siglo XIX, para dar paso a la estructura de las urbes modernas de la actualidad.

Eliminados los muros, se generaron nuevos espacios urbanos y de la función defensiva, continuando todavía con la de entorno portuario, se pasó a la lúdico-representativa. El mar, paulatinamente, dejó de ser el punto débil de fácil acceso para el enemigo y lugar sucio de vertidos residuales, para ser considerado una fuente de salud, tanto por sus baños terapéuticos como por los beneficios de sus brisas marinas, y un elemento para el ocio y el disfrute de la población. Esta novedosa concepción del mar generó una nueva relación de las ciudades litorales con el Mediterráneo que derivó en una apertura de la mismas hacia él, con la creación de paseos marítimos y todo tipo de servicios en torno a ellos.

La función lúdico-representativa iniciada en el siglo XIX cobró aún más importancia con el auge del turismo de sol y playa en la segunda mitad del siglo XX, desplazando definitivamente de nuestras fachadas marítimas urbanas la función defensiva y portuaria. Es el caso de Alicante, ciudad objeto de estudio en esta investigación.

\section{Delimitación del tema de investigación}

Se propone la cuestión de inicio de cómo ha llegado la fachada marítima portuaria a tener su actual morfología, qué factores han influido en ello, en qué momento se produjeron las transformaciones que derivaron en el litoral urbano de hoy, qué impacto tuvieron, en qué contexto histórico se desarrollaron y cuál ha sido el rol desempeñado por el frente costero con respecto al conjunto de la ciudad.

La hipótesis principal planteada es que las transformaciones morfológicas sufridas en el frente litoral portuario a lo largo del tiempo son el resultado de los cambios funcionales acaecidos, y dichos cambios, a su vez, han tenido un fuerte impacto en el conjunto de la estructura urbana.

\subsection{Objetivos, metodología y ámbito de estudio}

El objetivo destacado de la investigación es el estudio de la evolución de la fachada marítima urbana portuaria de Alicante para, analizando sus diferentes etapas, extraer las diversas funciones que ha desarrollado a lo largo del tiempo y cómo éstas la han ido moldeando e influyendo al mismo tiempo en el resto de la ciudad. En definitiva, se pretende dar respuesta a la cuestión de investigación planteada. 


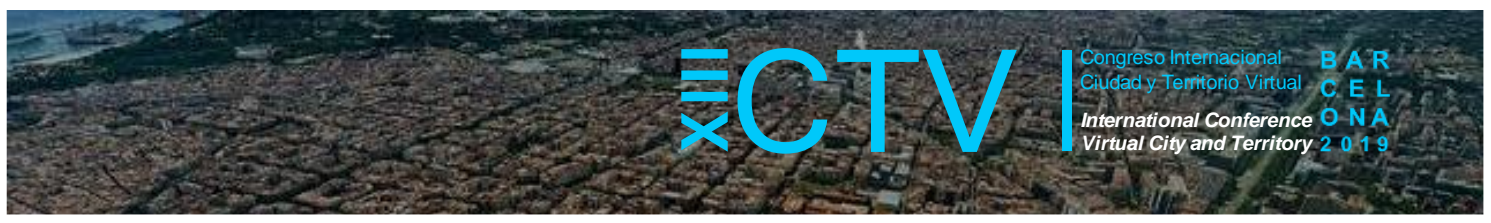

Este artículo se desprende de una investigación de mayor envergadura en relación al estudio de la génesis y evolución de la fachada marítima urbana de Alicante, que abarca un ámbito temporal más amplio y un análisis pormenorizado de los elementos urbanos y arquitectónicos que la componen. Las numerosas fuentes consultadas han aportado una comprensión profunda de la problemática abordada y una capacidad de síntesis de los procesos sufridos en el interfaz ciudad-mar. A través de escritos como el presente, se pretende reordenar toda la información extraída, estructurarla y exponer los resultados obtenidos para que las conclusiones derivadas nos ayuden a comprender el presente de nuestras fachadas marítimas, sentando las bases que nos permitan proyectar su, a menudo, controvertido futuro.

La metodología empleada se basa en el análisis pormenorizado de todos los elementos del frente litoral urbano alicantino. Se trata de una investigación descriptiva, ya que se estudian diversos aspectos de la fachada marítima, extrayendo sus características fundamentales. La variable elegida es la función, que estudiaremos para analizar cómo cambia la morfología de la fachada litoral portuaria. Diversas funciones nos darán diversas morfologías.

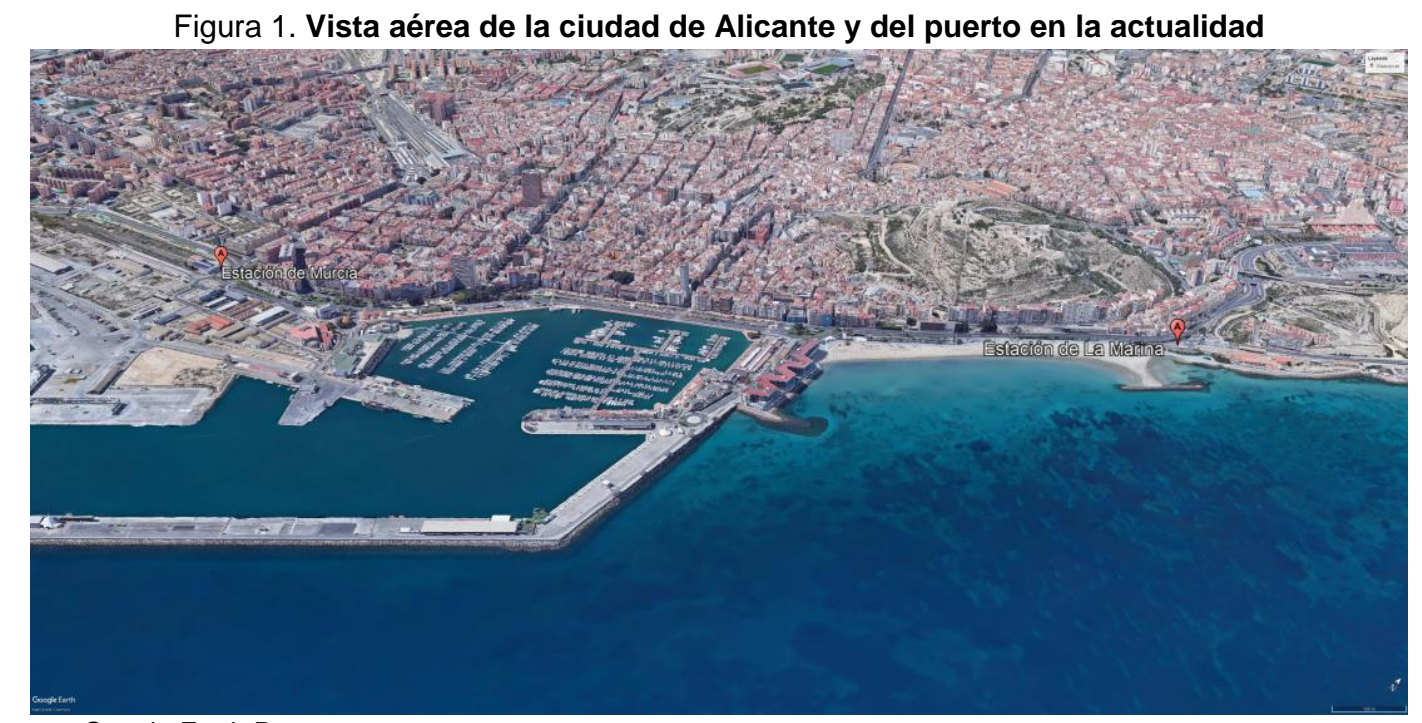

Fuente: Google Earth Pro

Con respecto al ámbito temporal, la investigación se centra en el período que se extiende desde el siglo XIX hasta nuestros días. La fachada marítima permaneció prácticamente invariable durante siglos. Será a partir deI XIX, con el derribo de las murallas, la expansión de la ciudad y la llegada del ferrocarril, cuando el frente experimentará importantes cambios hasta articular el espacio que conocemos hoy.

El ámbito espacial se limita al frente litoral propiamente urbano, es decir, el que abarcaría el casco histórico y los barrios adyacentes que quedaron englobados en él. Se podría considerar nuestro ámbito de estudio dividido en tres tramos principales, de este a oeste: paseo de Gómizpaseo de la Explanada-parque de Canalejas, de aproximadamente $870 \mathrm{~m}, 570 \mathrm{~m}$ y $540 \mathrm{~m}$ respectivamente -algo más de $2 \mathrm{~km}$ de longitud total- que enmarcan la ciudad en su límite con el mar y sirven, al mismo tiempo, de entorno al puerto de Alicante. Se tomarán como extremos de referencia las dos estaciones ferroviarias centenarias levantadas en la costa para facilitar el transporte de mercancías al puerto y que, aunque con otros usos, siguen en pie. Se trata de la estación de Murcia, actual Casa Mediterráneo, y la estación de La Marina, junto a la playa del Postiguet (Figura 1). 


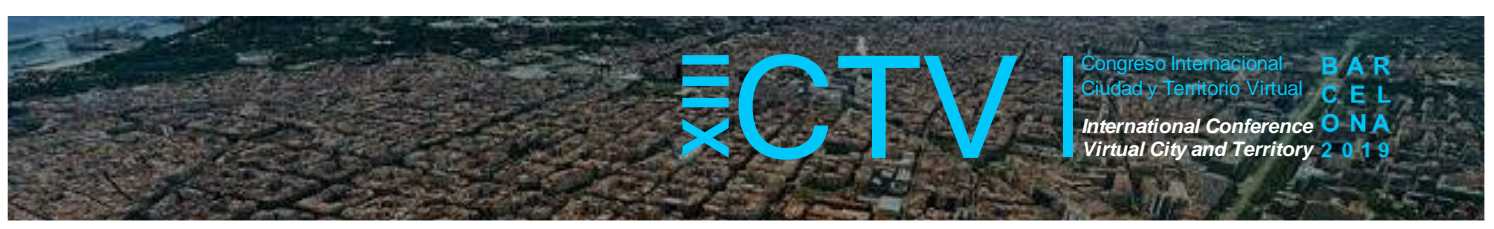

\subsection{Caso de estudio: Alicante}

Se ha elegido como caso de estudio la ciudad española de Alicante, capital de la provincia homónima y una de las tres que conforman la Comunidad Valenciana. Cuenta con un municipio con 201,27 km² y más de 200 km de costa bañada por el mar Mediterráneo, con una población de cerca de 500000 habitantes, considerando las localidades de la comarca próxima.

Si bien en el arco mediterráneo destacan metrópolis como Valencia o Barcelona, el caso de Alicante cuenta con la particularidad de haber sido una de las localidades costeras pioneras en la actividad turística, en gran parte debido a su temprana comunicación ferroviaria. Su estructura y evolución urbanas se pueden considerar equiparables a buena parte de ciudades del litoral mediterráneo.

\subsection{Concepto de fachada marítima}

Deteniéndonos en el significado estricto de los términos fachada marítima, si atendemos a la definición que de ambos vocablos hace el diccionario de la lengua española, fachada, en su primera acepción, significa 'paramento exterior de un edificio, especialmente el principal'. Dado que paramento es 'cada una de las dos caras de una pared' y marítimo, 'perteneciente o relativo al mar', podemos concluir que fachada marítima es 'la pared exterior de los edificios que dan al mar'. Se trata de un lienzo continuo que hace frente al mar, entendido como una unidad. Probablemente, no es casual que en otros idiomas -en inglés seafront o en italiano lungomare- exista un único vocablo para hablar de la fachada litoral.

Mies Van der Rohe se refería a la arquitectura como un problema de esqueleto y piel (Calduch, 2001), tratando la envolvente exterior — fachada - como una piel que recubre el esqueleto estructura-. La analogía entre ser vivo y edificio, extrapolable al conjunto de la ciudad, nos permite comprender que a menudo las fachadas se convierten en elementos representativos, ajenos a lo que está ocurriendo en el interior. $Y$ es que la imagen visual potente de la arquitectura está totalmente ligada a la imagen exterior de su piel, a su fachada (Figura 2). Puesto que un edificio viene definido exteriormente por su envolvente, la fachada marítima considerada un conjunto de envolventes puede definirse como la imagen visual de la ciudad 0 «el modo en que la ciudad se presenta en su límite con el mar» (Blasco, 1996, pág. 365).

Figura 2. Vista Acuarela «Vista de Alicante desde el Puerto». 1945. M. Balaguer (izda.). Vista actual de la dársena y paseo de la Explanada (dcha.)
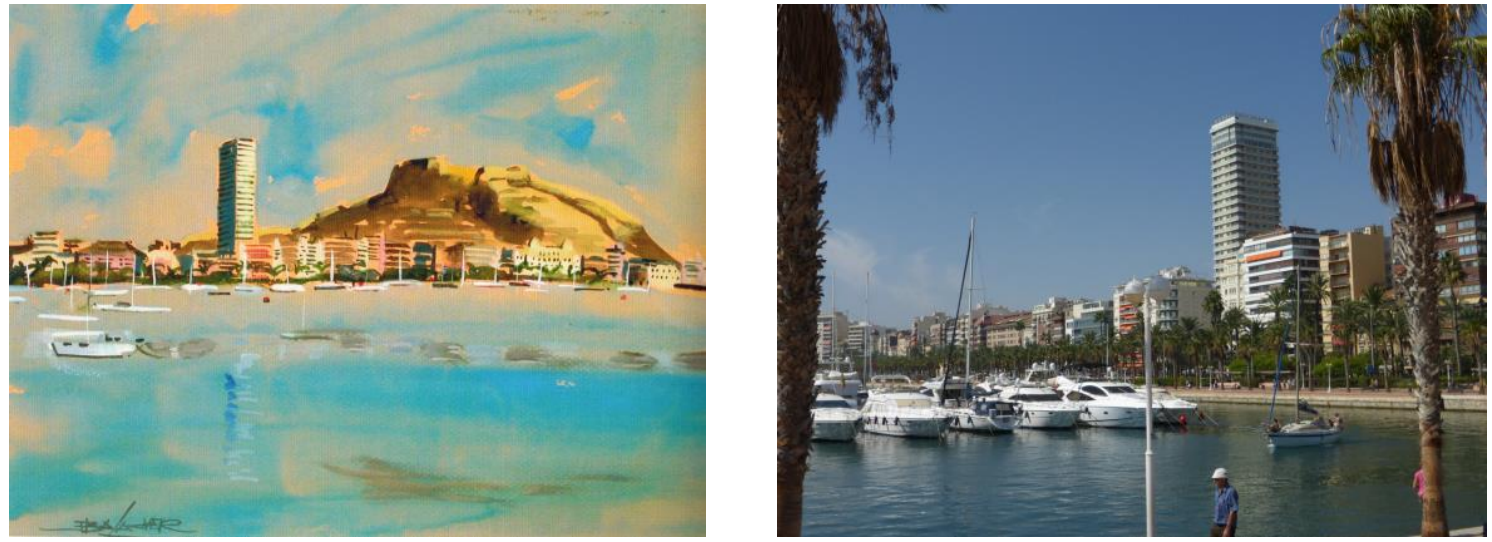

Fuente: Campos 2007, pág. 254 (izda.). Elaboración propia (dcha.) 


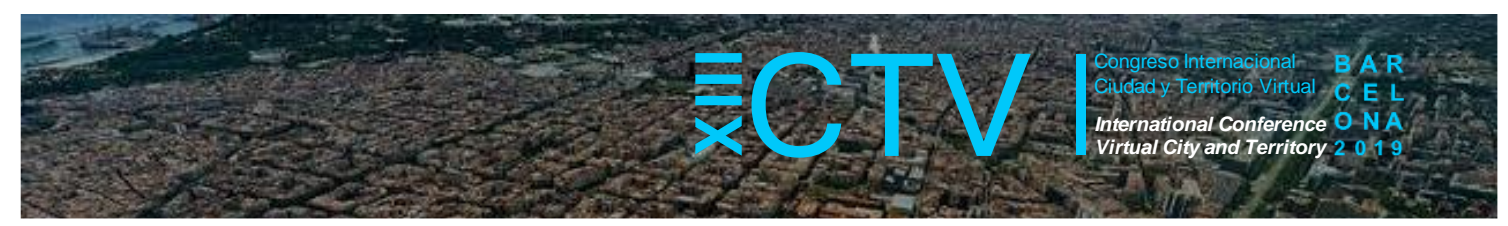

\section{Los orígenes de la fachada marítima: la función defensiva y portuaria}

El enclave actual de la ciudad de Alicante tiene sus orígenes en la antigua medina árabe surgida en el siglo VIII tras el Pacto de Tudmir ${ }^{2}$. Se trataba de un asentamiento litoral amurallado de reducido tamaño, Laquant, adosado al monte Benacantil que alojaba en su cima una alcazaba, que hoy en día permanece convertida en elemento representativo de la ciudad. Desde allí partía una muralla que bajaba por la ladera del monte hasta alcanzar la costa, rodeando las viviendas para procurarles protección (Ramos, 1984). En los siglos siguientes, la ciudad se extendió hacia el llano sorteando los accidentes geográficos y siguiendo la línea de la costa.

Como defensa frente a los ataques enemigos, se levantaron sucesivas murallas concéntricas con nuevas puertas y torreones - destacando las del siglo XVI-que fueron englobando a las anteriores, insuficientes para abarcar el cada vez más extenso perímetro urbano. Los rápidos avances en ingeniería militar dejaron en evidencia la obsolescencia del sistema defensivo, que quedó de manifiesto cuando un bombardeo de la armada francesa en 1691 arrasó completamente la ciudad. A partir de entonces, y tras varios proyectos de obras militares del que sólo se ejecutó un baluarte -el de San Carlos, junto a la costa-, los esfuerzos por mejorar la estructura de defensa urbana se limitaron a la construcción de un nuevo anillo mural, mucho más sencillo, y al refuerzo de los existentes.

Destacar además que, desde sus orígenes, la ciudad está íntimamente ligada a su puerto, no se entiende la evolución de la urbe sin su enclave portuario y viceversa. Ya el rey Alfonso X el Sabio declaró Alicante Puerto Público del Mediterráneo en 1271 y de 1433 es el primer escrito documentado sobre el mismo en su emplazamiento actual. Lo que comenzó siendo un muelle de madera de 200 pasos, ubicado junto a la puerta de la muralla conocida como Puerta del Mar —donde actualmente está el de Levante-, con el paso de los años fue ganando en longitud, tamaño y capacidad (Subirá, 1987). Tras la intensa actividad de los siglos XIV y XV —el de Alicante era el segundo puerto del país-, continuó como punto de escala en el comercio con América y exportador de productos locales y castellanos.

Fue en el siglo XIX cuando experimentó la primera renovación profunda para adaptarlo a las nuevas exigencias de los barcos de vapor, de mayor tamaño y calado y con mayores necesidades espaciales para acopio de mercancías en tierra. Coincidiendo con el traspaso de competencias de las autoridades militares a las civiles, se realizaron obras de prolongación del muelle de Levante y se inició la construcción del contramuelle, el de Poniente, conformando la dársena que conocemos hoy.

Durante los primeros años del siglo XX se levantaron edificios portuarios singulares - como la Ionja, que perdura con otros usos-, a la vez que se solucionaban los problemas de vertido en el puerto de aguas residuales de la ciudad y se continuaba con la ampliación hacia el sur del muelle de Poniente. A partir de los años 50, las necesidades de grandes superficies de descarga por la introducción de derivados del petróleo, el tráfico de mercancías a granel y el empleo de contenedores, derivó en la aparición de un nuevo enclave portuario consistente en

\footnotetext{
${ }^{2}$ El Pacto de Tudmir o de Teodomiro firmado el 5 de abril del año 713 entre Abd al-Aziz ibn Musa, hijo del gobernador del norte de África, y Teodomiro, noble visigodo, dio lugar a un territorio de dominio musulmán con cierta autonomía, que serían aproximadamente las actuales provincias de Alicante y Murcia.
} 


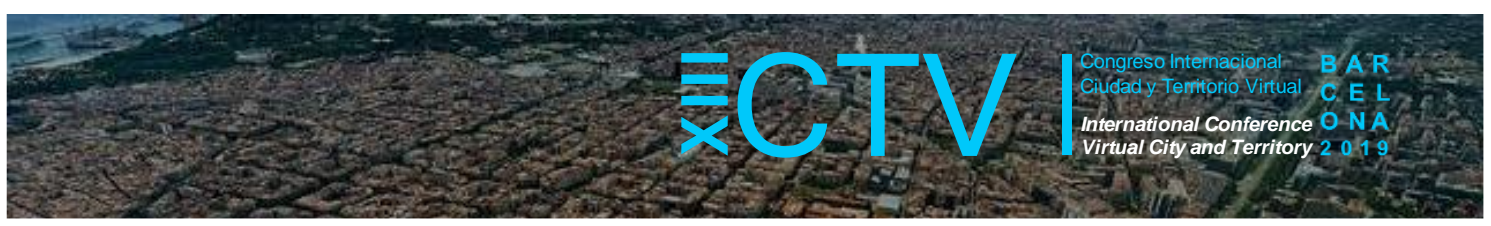

grandes plataformas de terreno ganado al mar al sur de la ciudad, que desde entonces no ha parado de crecer.

La transformación reciente más importante se llevó a cabo en los años 90 con el Plan Especial del Puerto, con el que se trasladó definitivamente toda actividad portuaria al sur del núcleo urbano, reconvirtiendo los muelles en espacios para centros comerciales y de ocio y la dársena en marina deportiva para embarcaciones náuticas y de recreo. A partir de ese momento, el puerto histórico se erigió como punto turístico donde se concentra buena parte de la oferta hostelera y eventuales actividades náuticas, como la salida de la Vuelta al Mundo a Vela Volvo Ocean Race-. La función del frente litoral de servir de entorno al puerto, como ocurrió con la defensiva a mediados del siglo XIX, había llegado a su fin.

\section{Las transformaciones del siglo XIX: la función lúdico-representativa}

Aunque con retraso, dada su condición de capital de provincia, la Revolución Industrial habría de llegar también a Alicante. A mediados del siglo XIX, la provincia contaba con diversas localidades industriales, era rica en materias primas y productos agrícolas y tenía cierta actividad minera. La ciudad, protegida por las murallas y el castillo de Santa Bárbara considerado entonces la plaza fuerte más importante del Reino de Valencia- estaba dotada de todos los servicios necesarios, con una estructura urbana organizada y una población de casi 20000 personas, que no cesaba de aumentar gracias a la favorable situación económica.

\subsection{La llegada a la costa del ferrocarril}

Pese a contar con un puerto comercial de primera clase, Alicante carecía de una buena comunicación con el interior. Debido en gran parte a la escasez de obstáculos a salvar y a la suave orografía del terreno, conectar Madrid con el puerto de Alicante fue la opción más ventajosa frente a otras localidades costeras. Tras la implantación de las líneas ferroviarias por toda Europa y la inauguración del primer trayecto en tren en la península en 1848 entre Barcelona y Mataró, se desarrolló la línea ferroviaria entre Madrid y Alicante en 1858, convirtiéndola en la primera ciudad litoral española unida por este medio con la capital. Gracias al ferrocarril, la ciudad amplió su territorio de influencia de las comarcas limítrofes a las provincias cercanas y al interior de la península.

Figura 3. Muelle de Levante con vagones de carga. Puerto de Alicante. 1910 (izda.). Ferrocarril por la fachada marítima. 1947 (dcha.)
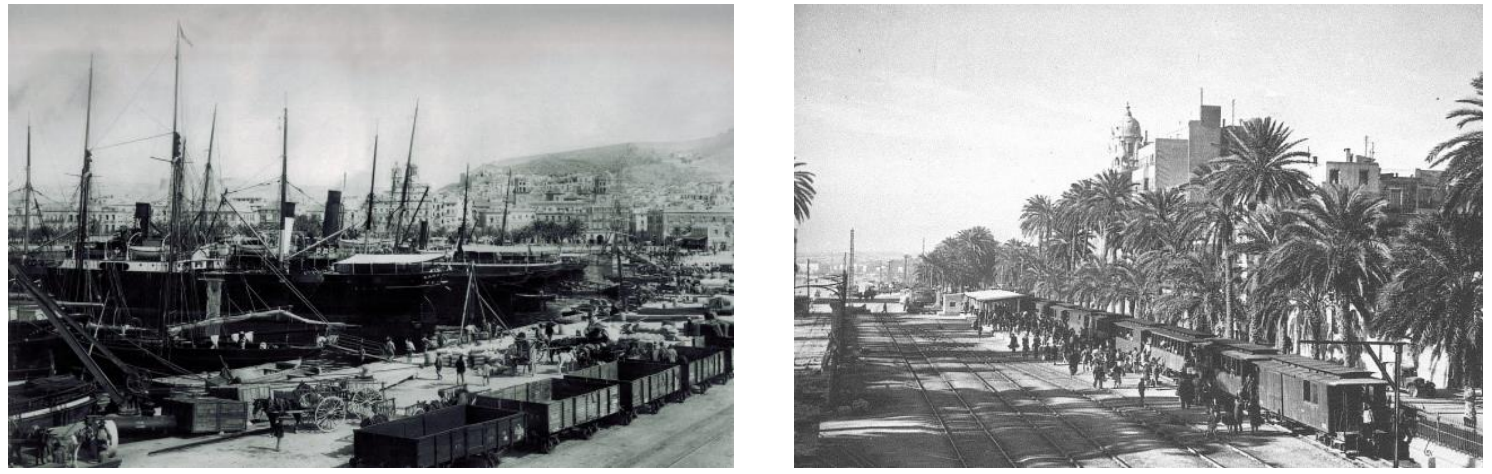

Fuente: Archivo Municipal de Alicante. Colección M. Cantos (izda.) y colección F. Sánchez (dcha.) 


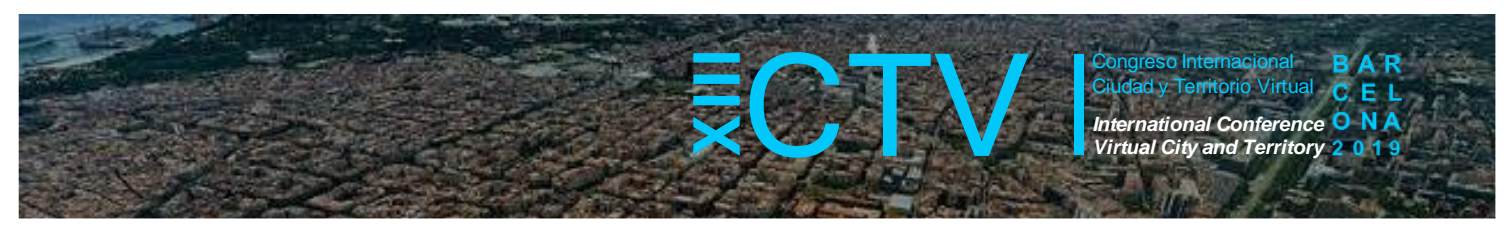

Si bien, por motivos técnicos, la estación término se situó en el interior, no tardó en instalarse un ramal que conectaba con los muelles y que dio lugar a la importante red logística del puerto configurada por un anillo ferroviario que, discurriendo por la fachada marítima y envolviendo la dársena, enlazaba con las carreteras de Alicante y con las dos estaciones que nos sirven de límite en el ámbito de estudio: la de Murcia, hacia el sur; y la de La Marina, hacia el norte (Aguilar, 2008). Habría de pasar más de un siglo para que el ferrocarril desapareciera completamente del frente litoral (Figura 3), ganando ese espacio para la ciudad y para el turismo de masas que habría de llegar.

\subsection{El derribo de las murallas y la extensión de la ciudad}

A mediados del siglo XIX el recinto amurallado se había revelado insuficiente para acoger a la creciente población, que cada vez ocupaba más terreno extramuros. Aprovechando la visita de la reina Isabel II a la ciudad en 1858 para inaugurar la línea ferroviaria, se le solicitó el derribo de las murallas y ésta concedió que Alicante dejara de ser plaza de guerra, con lo que se procedió al derribo total de las mismas.

El Plan de Ensanche de Alicante, de 1890, aplicado de forma tardía e ineficaz, no acometió las reformas urbanas profundas que la ciudad necesitaba y la corriente higienista propugnaba. Excepción a ello fueron los paseos litorales, que se consolidaron como espacio elegido por buena parte de la burguesía local para establecer sus residencias. Al contrario de lo sucedido en otras ciudades, el binomio Ensanche-Modernismo no se dio del todo en Alicante.

\subsection{El auge de los baños de mar: el origen del turismo}

La aparición del ferrocarril como medio de transporte acortó las distancias entre poblaciones y facilitó el desplazamiento de personas y mercancías, transformando muchas ciudades de la costa en lugares de recreo y servicios. En estrecha relación con la incorporación del tren a la vida urbana está la moda de los baños de mar y el turismo de balnearios, que se produjo de forma coetánea en la segunda mitad del siglo XIX.

Retomando el hábito de antiguas civilizaciones, las clases altas inglesas de finales del siglo XVIII instauraron la moda de los baños termales como fuente de salud, que pronto se extendió por toda Europa dando lugar a un nuevo modelo de ciudad, la ciudad-balneario, origen de lo que se conoce hoy como turismo de salud. Ejemplos de ello son la inglesa Bath, la bohemia Karlovy Vary o la francesa Vichy. De la explotación de las aguas mineromedicinales se pasó a las marinas, mucho más accesibles y populares, con la creación de muelles y plataformas sobre la costa, a modo de zonas de recreo, como el pionero chain pier de Brighton de 1823.

En España la burguesía adoptó la costumbre aristocrática de cambiar de residencia a lugares del litoral en época estival, identificándose los baños de mar con una clase social con alto poder adquisitivo. Apareció así el concepto de segunda residencia y muchas poblaciones del Mediterráneo - como Murcia, Tarragona o Alicante- se convirtieron en destino de veraneo. Este hábito modificó definitivamente la morfología urbana de estas ciudades, reflejando el modelo de ciudad-balneario, como en el caso de Alicante, en su fachada marítima. Largos paseos marítimos, balnearios sobre el mar (Figura 4), instalaciones deportivas, casinos, hoteles, restaurantes, cafés, teatros de verano etc., cuajaban la fachada litoral para dar servicio a los nuevos visitantes que llegaban a tomar los baños, normalmente bajo prescripción médica. 


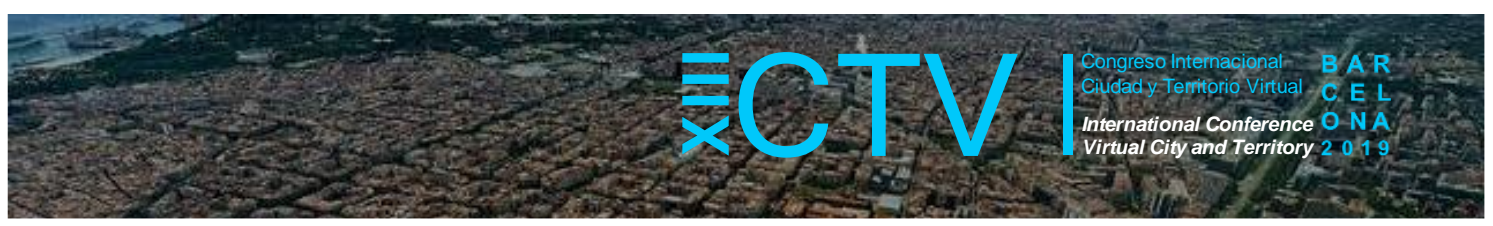

Figura 4. Balnearios en la playa del Postiguet, Alicante. 1900 y 1968
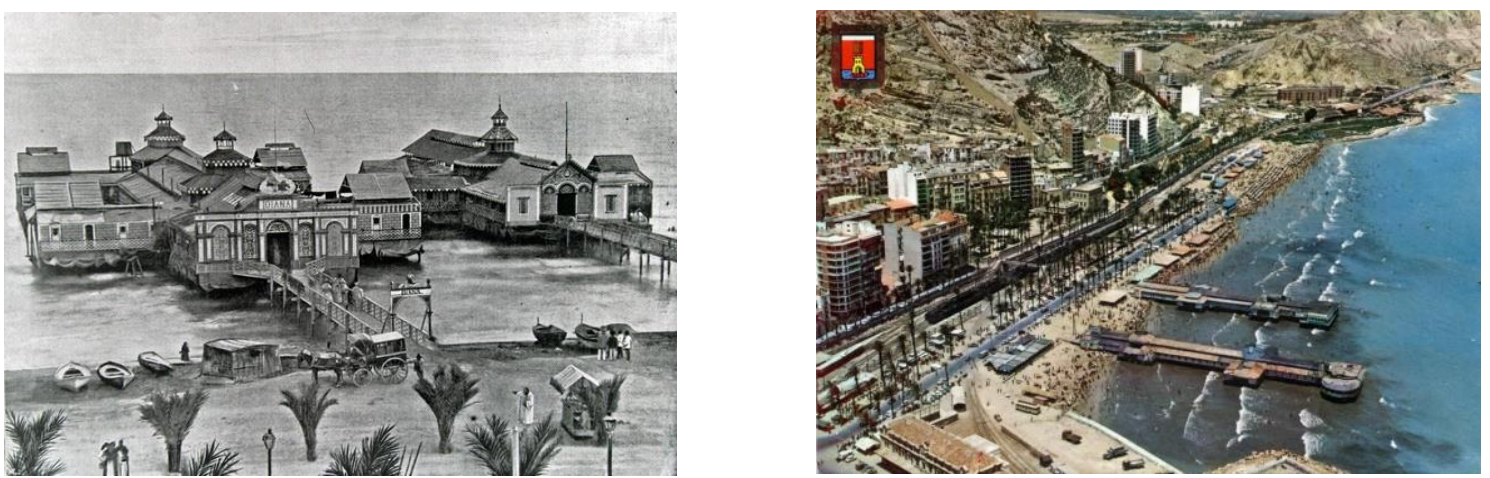

Fuente: Archivo Municipal de Alicante. Colecciones F. Sánchez (izda.) y E. Bañón (dcha.)

Con la aparición de un tren turístico de bajo coste — conocido popularmente como tren botijoa partir de 1893, las estancias en Alicante para tomar los baños se extendieron a las clases populares. Este tren de billete económico, que funcionó hasta 1917 con una media de 30000 viajeros al año, supuso la consolidación de Alicante como destino estival, al que muy pronto se unieron otras localidades del litoral.

\section{La fachada marítima representativa: los paseos litorales}

En el contexto en el que se inscribe, la urbanización de los paseos marítimos conformando un interfaz ciudad-mar unificado y continuo, se convirtió en paradigma del proceso de modernización de la ciudad. Se trataba de paseos arbolados, que recibían el nombre de jardínbulevar, muy en boga en la Europa del siglo XIX. Herederos de las alamedas de épocas ilustradas y materialización de las ideas higienistas, eran fiel reflejo de la concepción burguesa de la ciudad, donde los jardines se hacían públicos, higiénicos y con vegetación para el disfrute de la naturaleza por parte de toda la población (Jaén, 2014).

Desde su creación, se distinguen tres paseos principales en la fachada marítima de Alicante: el de la Explanada, tramo central, primero en ser urbanizado y protagonista indiscutible; el parque de Canalejas, prolongación hacia el sur del anterior; y el paseo de Gómiz, junto a la playa del Postiguet.

\subsection{El paseo de la Explanada de España}

Se trata de un paseo que se extiende, siguiendo la línea litoral, desde el monumento a Canalejas - donde antaño estuvo el baluarte de San Carlos - hasta la plaza de la Puerta del Mar. Conocido en sus inicios como Malecón, ya aparece representado en el plano de $\mathrm{M}$. Mirallas de 1794 como una plataforma ganada al mar, proyecto que no se vio materializado hasta 1833, con el derribo de las murallas litorales y el uso de los escombros resultantes para la nivelación del terreno. En esta nueva superficie de ciudad ganada al mar se crearon dos calles paralelas a la línea de la costa, la de San Fernando — por el interior-, y el Malecón frente al mar-. Tras años de enfrentamiento entre las autoridades militares, que consideraban la zona como parte del área defensiva, y las municipales, que se proclamaban con derechos sobre los nuevos terrenos, finalmente se prohibió la edificación y se decidió la urbanización de un paseo para la ciudad. 


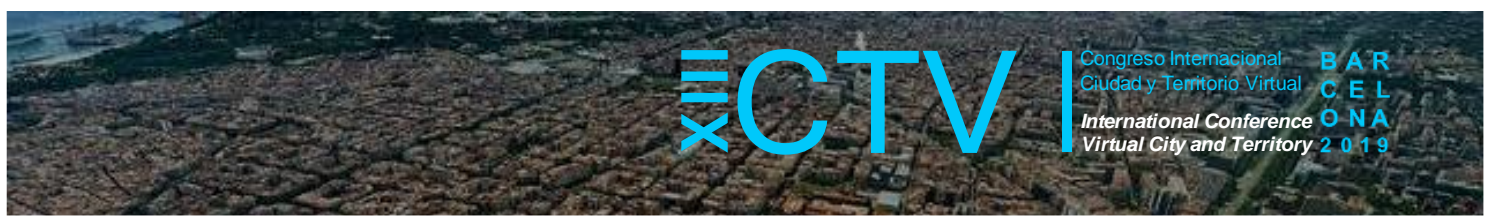

Las primeras viviendas edificadas en el Malecón en la primera mitad del siglo XIX eran de tipología sencilla, con tres plantas a lo sumo y ligera ornamentación de corte clasicista en sus fachadas (Aldana, 2014). Alguna de ellas era vivienda-almacén con acceso desde la calle San Fernando, ya que aún no estaba urbanizado el Malecón, sirviendo de residencia a los comerciantes ligados a la actividad portuaria. Cuando las alineaciones se lo permitieron, estos propietarios ampliaron varios pisos para hacer viviendas con fachada al nuevo Malecón.

A partir de la segunda mitad del siglo XIX, sin abandonar el clasicismo, la sobriedad en la ornamentación de fachadas dio paso a una profusión de elementos decorativos. Ambas calles paralelas al mar, Malecón y San Fernando, fueron tratadas en sus lienzos exteriores de similar manera, con monumentalidad y muestra visible del poder económico de sus moradores. En esta época se instalaron en el paseo instituciones como el Casino de Alicante, hoteles de cierto renombre y residencias de familias burguesas, sembrando el germen de la nueva fachada marítima de la ciudad.

La primera fase urbanizadora del Malecón concluyó en 1868. Lo que hasta entonces había sido lugar de vertido de escombros y suciedad ligado al puerto, se convirtió en un agradable bulevar de palmeras elegido como punto de reunión por la población. Tras el derribo de los mercados junto al puerto en 1910 se pudo prolongar el paseo, dándole la longitud actual, edificando en su solar la Casa Carbonell, uno de sus edificios residenciales más emblemáticos.

Alicante, duramente castigada durante la Guerra Civil española, fue destino de acogida de refugiados y último puerto de salida para su evacuación. El fin de la guerra fue anunciado sólo dos días después que zarpara del puerto el ultimo barco rumbo al exilio y de la entrada de las tropas nacionales en la ciudad, por lo que se podría afirmar que la fachada marítima fue escenario de los últimos acontecimientos de la contienda. A los duros años bélicos, siguió la Posguerra, época de dificultad económica y reconstrucción de la ciudad.

La característica distintiva del paseo, su pavimento de mosaico de mármol tricolor formando ondulaciones, fue incorporado en los años 50 (Figura 5). Posteriormente, se ganó más terreno al mar, lo que permitió ampliar el muelle de costa y mejorar la carretera del litoral, favoreciendo la comunicación con el puerto. A la vez, se produjo una paulatina sustitución de los edificios residenciales originales, incorporando incluso edificios singulares en altura, que modificaron drásticamente el perfil de la ciudad.

Figura 5. Paseo de la Explanada (izda.), parque de Canalejas (centro) y paseo de Gómiz (dcha.)
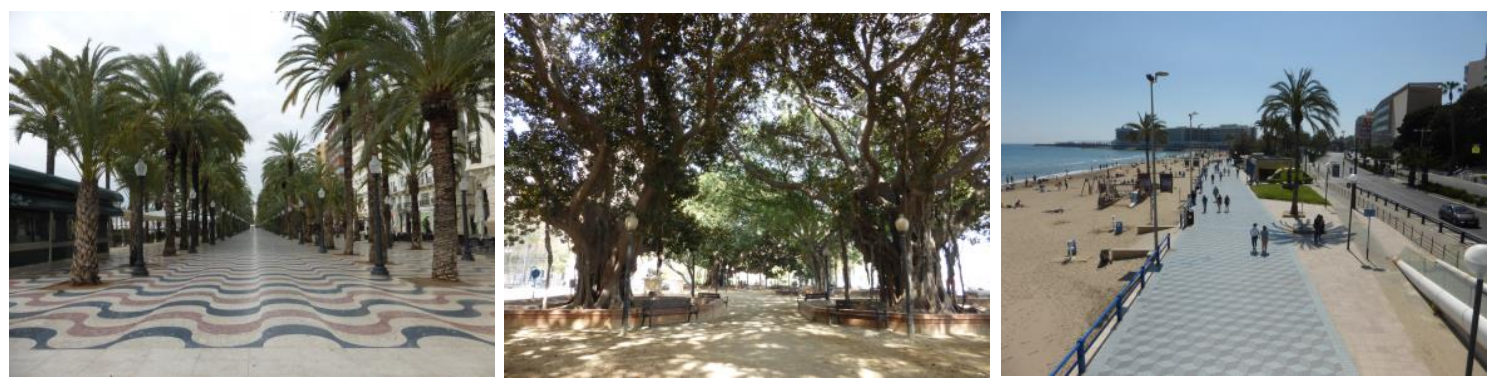

Fuente: Elaboración propia 


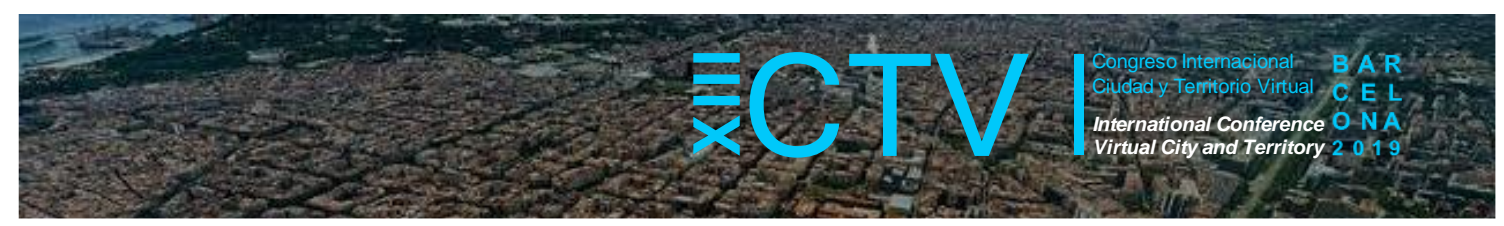

\subsection{El parque de Canalejas}

El éxito de la Explanada propició que, apenas unos años después, se prolongara el mismo hacia el suroeste en forma de bulevar que ha llegado hasta nuestros días. Situado al sur de la zona del Ensanche, en principio fue una explanada junto al puerto que servía de varadero y lugar de acopio de mercancías del puerto. Convertido en parque-paseo en 1891, se le dio una estructura -que permanece casi inalterada - de salón central con hileras longitudinales de pinos y palmeras paralelas a la costa y circulación de carruajes en los laterales.

El hecho de que el baluarte de San Carlos, límite físico del parque, no fuera derribado completamente hasta bien entrada la segunda mitad del siglo XIX y que el último tramo de la calle San Fernando - trasera de las manzanas del parque- se abriera muchas décadas después que el resto, hicieron que el desarrollo de este paseo fuera muy diferente al de la Explanada. Sus edificaciones originarias, más que viviendas-almacén, eran residencias de familias burguesas o edificios para alquiler de viviendas a particulares, como la casa Alberola que perdura parcialmente. A la vez, diversas compañías de exportación, alentadas por la cercanía del puerto y del espacio de acopio de mercancías, se establecieron en la zona, conviviendo en las primeras décadas del parque almacenes y residencias.

El paseo de Canalejas es una de las áreas verdes de mayor tamaño y más antigua que se conserva en la ciudad, aunque al estar más alejada del núcleo histórico y de la playa, y debido a su morfología de parque arbolado (Figura 5), más que de paseo, suele ser menos transitada que la Explanada.

\subsection{El paseo de Gómiz}

Como prolongación de la Explanada, esta vez hacia el noreste, a partir de 1890 se urbanizó el paseo marítimo que hacía de marco a la playa de la ciudad, el Postiguet. Nació como materialización de la idea higienista original de fachada continua y monumental, a la vez que servía de acceso a los numerosos balnearios que poblaban la playa desde finales del siglo XIX. No obstante, la proximidad del monte Benacantil y del barrio humilde de su ladera -cuyas edificaciones hacían de frente marítimo-, sumado a la barrera que suponían las vías del ferrocarril junto al paseo, le confirieron características particulares.

A partir de los años 30, debido a un cambio en los hábitos sociales y a la aparición de nuevos tratamientos de salud, los baños de mar entraron en decadencia. A todo ello contribuyó la aparición del automóvil, que en poco tiempo entró a formar parte de la vida cotidiana, facilitando el acceso a cualquier emplazamiento más allá de donde el tren podía llegar.

En los años 60 y 70, con el auge del turismo de sol y playa, las sombrillas y chiringuitos sustituyeron a los balnearios. La barrera de las vías del tren fue desmantelada, pero en su lugar el tránsito de vehículos por el vial longitudinal paralelo a la playa - N-332- fue en aumento (Figura 5). Desde el primer Plan General de Ordenación Urbana de la ciudad de 1956, se ha abordado sin éxito el problema del frente litoral —el intenso tráfico, la desconexión con el resto de la ciudad, el entorno portuario, etc.- con propuestas de conexiones peatonales, soterramientos e incluso túneles submarinos para la circulación rodada que no se han llegado a ejecutar. No obstante, a pesar la problemática no resuelta, el paseo de Gómiz es uno de los espacios más concurridos de la ciudad. 


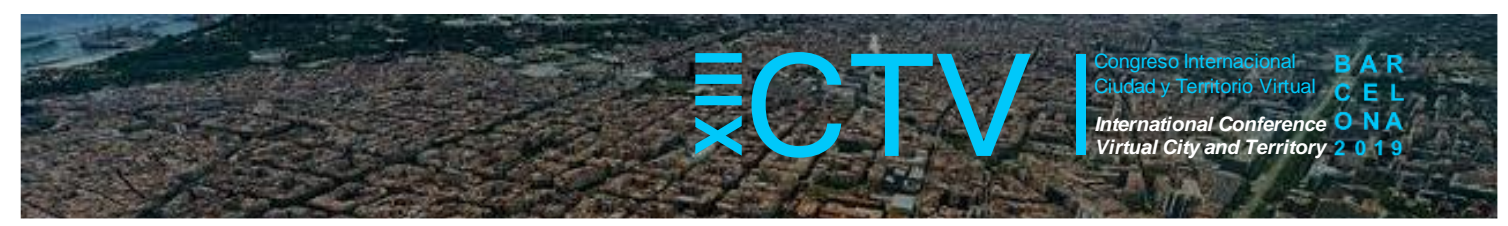

\section{Conclusiones}

Las fachadas marítimas urbanas de numerosas ciudades del arco mediterráneo desempeñaron durante muchos siglos una mera función defensiva, de protección frente a los ataques enemigos, compaginada con la función de servir de entorno a su puerto, fuente de riqueza y sustento primordial de la economía de su hinterland. Es el caso de Alicante, que hasta que se autorizó, bien entrado el siglo XIX, el total derribo de sus murallas y elementos defensivos que la encintaban —cuando ésta dejó de ser plaza fuerte— no comenzó el proceso de reconversión de su fachada marítima.

La incorporación del ferrocarril a la ciudad reactivó la actividad portuaria a la vez que, gracias a la aparición de un billete de bajo coste, convertía la ciudad en destino preferente de los habitantes del interior que llegaban a la costa para tomar los baños de mar, tan de moda entonces. La llegada, cada vez más masiva, de visitantes transformó la fachada litoral en el lugar de su recreo a la vez que la burguesía local elegía instalar sus residencias frente al mar. Y es que, en las últimas décadas del siglo XIX, en línea con las ideas higienistas imperantes en la época, el frente marítimo se había convertido en un hermoso bulevar de palmeras, centro de atracción de la actividad social de la ciudad. La función lúdico-representativa no había hecho más que comenzar.

Tras el declive de los balnearios, y el paréntesis que supuso la Guerra Civil y la Posguerra, se entró en un período de decadencia que se trató de paliar con la reconversión total de la fachada litoral en los años 90. Fue en esta década cuando se actuó sobre el frente portuario urbano de forma generalizada, reconvirtiendo los antiguos muelles en centros comerciales y de ocio de dudoso éxito, a la vez que se destinaba la dársena a marina deportiva y se desplazaba la actividad portuaria hacia el sur de la ciudad. Desde entonces la superficie portuaria no ha parado de crecer, conformando unas instalaciones que, si bien no entorpecen la actividad de núcleo urbano, se han hecho con el dominio de la fachada litoral sur, impidiendo la natural continuidad de la totalidad del frente costero.

Uno de los principales problemas al que se enfrentan las ciudades litorales de tradición portuaria e importante actividad turística es que, por diversos motivos, ha habido que reubicar las instalaciones del puerto fuera del núcleo urbano y dar una nueva función al complejo de tinglados, muelles y edificios portuarios que su traslado ha dejado vacante. En ese importante paso, a menudo no se ha sabido aprovechar el potencial de esos nuevos espacios de uso para la ciudad -con proyectos en los muelles de edificios comerciales fuera de la escala urbana y completamente desconectados de la urbe-, a la vez que se descuidaba el planeamiento y el impacto urbano y socio-económico de los recientes enclaves portuarios en su área de influencia.

Se plantea la necesidad de un trabajo conjunto de las autoridades competentes -locales, autonómicas y estatales-, portuarias y municipales, para, evitando cualquier conflicto de intereses, restablecer las conexiones naturales históricas puerto-ciudad, reconvirtiendo definitivamente las fachadas marítimas urbanas portuarias en espacios vivos ganados para la ciudad.

Conflicto de Intereses: La autora declara que no hay conflicto de intereses. 


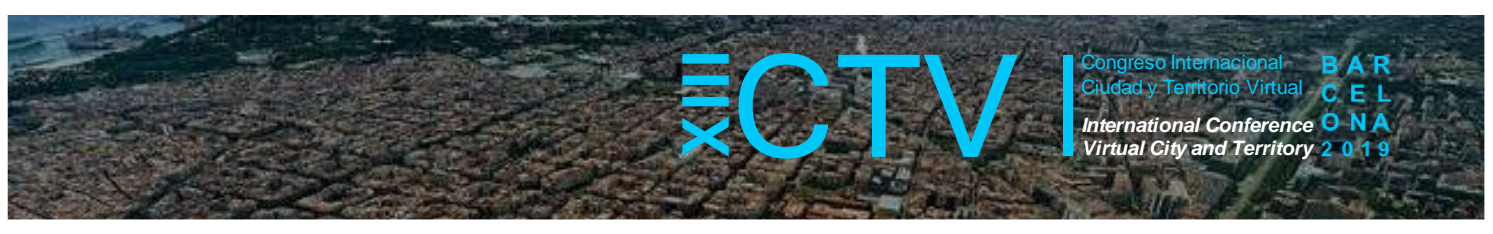

\section{Bibliografía}

Aguilar, I. (2008). 150 años de ferrocarril Alicante-Madrid. Valencia, España: Cátedra Demetrio Ribes, UVEG-FGV y Generalitat Valenciana.

Aldana, S. (dir.) et al. (2004). Monumentos desaparecidos de la Comunidad Valenciana. Alicante. Valencia, España: Generalitat Valenciana, Consell Valencià de Cultura.

Blasco, C. et al. (1996). El frente marítimo de la ciudad de Alicante. En Jornadas de Geografía Urbana (pp. 365-378). Alicante, España: Biblioteca virtual Miguel de Cervantes.

Calduch, J. (2001). Temas de composición arquitectónica. Luz, sombra, color, contorno. Alicante, España: Editorial Club Universitario.

Campos, S. (2007). Historia Gráfica del Puerto de Alicante. Madrid, España: Autoridad Portuaria de Alicante.

Jaén, G. y Gutiérrez, P.J. (2014). Jardines románticos en Alicante. Canelobre, 64, (pp. 468481).

Ramos, A. (1984). Evolución urbana de Alicante. Alicante, España: Instituto de estudios Juan Gil-Albert y Diputación Provincial de Alicante.

Subirá, G. (1987). Evolución histórica del puerto de Alicante. Alicante, España: Caja de Ahorros Provincial de Alicante. 